\title{
A globally networked hybrid approach to public health capacity training for maternal health professionals in low and middle income countries
}

Scott McIntosh ${ }^{1 *}$ (D) José G. Pérez-Ramos ${ }^{2}$, Tamala David ${ }^{3,4}$, Margaret M. Demment ${ }^{5}$, Esteban Avendaño ${ }^{6}$, Deborah J. Ossip ${ }^{1}$ and Timothy De Ver Dye ${ }^{2}$

\begin{abstract}
Background: MundoComm is a current $\mathrm{NIH}$-funded project for sustainable public health capacity building in community engagement and technological advances aimed at improving maternal health issues. Two to four teams are selected annually, each consisting of three healthcare professionals and one technical person from specific low and middle income countries (LMICs) including Costa Rica, Dominican Republic, Honduras, and other LMICs. MundoComm is a course with three parts: in-person workshops, online modules, and mentored community engagement development. Two annual 1-week on-site "short courses" convened in Costa Rica are supplemented with six monthly online training modules using the Moodle ${ }^{\circledast}$ online platform for e-learning, and mentored project development. The year-long course comprises over 20 topics divided into the six modules - each module further segmented into 4 week-long assignments, with readings and assigned tasks covering different aspects of community-engaged interventions. The content is peer reviewed by experts in the respective fields from University of Rochester, UCIMED in Costa Rica, and faculty from Costa Rica and the Dominican Republic who maintain regular contact with the trainees to mentor learning and project progress. The purpose of this paper is to report the first year results of the MundoComm project.
\end{abstract}

Methods: Both quantitative and qualitative feedback (using online data capturing forms) assess baseline and posttraining knowledge and skills in public health project strategies.

Results: The course currently has one team each in Costa Rica, the Dominican Republic, and Honduras for a total of 12 trainees. The course and modules include best practices in information and communication technologies (ICTs), ethical reviews, community engagement, evidence-based community interventions, and e-Health strategies. To maximize successful and culturally appropriate training approaches, the multi-media didactic presentations, flexible distance learning strategies, and the use of tablets for offline data collection are offered to trainees, and then feedback from trainees and other lessons learned aid in the refinement of subsequent curricular improvements.

Conclusions: Through remark and discussion, the authors report on 1) the feasibility of using a globally networked learning environment (GNLE) plus workshop approach to public health capacity training and 2) the capacity of LMIC teams to complete the MundoComm trainings and produce ICT-based interventions to address a maternal health issue in their respective regions.

\footnotetext{
*Correspondence: scott_mcintosh@urmc.rochester.edu

${ }^{1}$ Department of Public Health Sciences, University of Rochester Medical

Center, 265 Crittenden Blvd., CU 420644, Rochester, NY 14642, USA

Full list of author information is available at the end of the article
} 


\section{Background}

In many low and middle income countries (LMICs) where health is improving more slowly compared to wealthier countries, international health disparities increase. Improvements in child and maternal mortality, for example, have stagnated in several countries and, although a trained workforce of health professionals is essential to successfully address this, there is currently a lack of adequate capacity [1].

Costa Rica, which has emerged as a regional hub for technology and health in Latin America [2, 3] serves as the setting for on-site training and host of the online training modules for the current project. This training initiative, called MundoComm, is funded by the National Institutes of Health (NIH) and links a US-based project team with an expanded team of informatics faculty that includes Fellows/Trainees from our previous projects in Costa Rica and the Dominican Republic [4-6]. With this experienced partnership team, the aims of MundoComm are to train and demonstrate the successful use of Information and Communications Technology (ICT) for maternal health improvement throughout the Latin American region. Despite progress in other areas of maternal and child health, this region faces ongoing poor profiles of maternal mortality rates [7].

Elsewhere such technological innovations as m-Health and internet-based technologies have improved maternal health $[8,9]$. Our partners in Costa Rica, the Dominican Republic and in other areas of Latin America (e.g., Honduras, Mexico) are eager to demonstrate feasibility of such technological innovations for specific populations and regions where maternal health is challenged, particularly in the indigenous communities, rural communities, and among the African-Caribbean population.

MundoComm's primary aims are:

1. To develop a mentored training program for community-based public health applied research teams from high-need areas of Costa Rica, the Dominican Republic, Honduras and elsewhere in Latin America to learn about ICT applications, with specific reference to maternal health;

2. To test specific training team ICT innovations in field settings to demonstrate feasibility and appropriateness for local context;

3. To create a "Collaboratory" environment where teams, faculty, experts, and others to share developing material, comment on plans, suggest alterations and developments, discuss barriers, and provide support for trainees in the innovation process; and,

4. To stimulate development of a professional network of ICT, medical, public health, and community students, faculty, researchers, and practitioners devoted to supporting ICT for Maternal Health in Latin America.

The theoretical orientation of MundoComm blends Team Learning Theory (TLT) $[10,11]$ with CommunityEngaged Research (CER) $[11,12]$ to create a mentored, experiential training year where local teams of professionals develop an ICT innovation for their area and context. Both TLT and CER directly contribute to the lasting sustainable effects of MundoComm. Teambased learning and the community-engagement process invests in groups of people, with distinct but overlapping roles, so that there is common exposure and group experience that promotes institutional memory, cross-training, and succession planning $[13,14]$. Should a team member leave, teams can take on new members without requiring new members to repeat the entire training, rather their induction can involve completing the online modules and reviewing archival materials, with mentoring provided by other team members.

The objective of the present analysis is to explore and report upon the first year results of the MundoComm project. GNLEs (globally networked learning environments) are highly goal-based learning environments that incorporate innovation and technological change. The feasibility of combining a GNLE and workshop approach to public health capacity training, and the capacity of LMIC teams to complete the Mundocomm trainings and produce ICT-based interventions to address a maternal health issue in their respective regions is useful not only to the current project team, but hopefully exportable to other project teams in other LMIC settings. The University of Rochester's Research Subjects Review Board reviewed the project and determined that the project does not qualify as human subjects research (45 CFR 46.102) in that the activities do not meet the federal definition of research.

\section{Methods}

The MundoComm project

The aims of MundoComm are to create a "Collaboratory" [15] - with both online and in-person occasions for interaction, mentoring, sharing of technology, and the expansion of existing distance-learning resources. Through MundoComm, the partnerships and areas of expertise aims to test, evaluate, and provide integrated technological and public health training simultaneously through in-person and online methods to local teams in high-risk areas with multiple professional roles represented ("integrated teams"). By training multiple people across role types from different communities, the project aims to maximize chances of impacting institutional sustainability, and assuring community engagement. 


\section{The MundoComm curriculum}

In the Collaboratory context described above, MundoComm is implementing 1) workshops, 2) online training, and 3) a mentored community training. Two week-long short courses each year are provided to address intervention development and evaluation, health registry development, technology assessment, and ICT project management. These are presented to project teams inperson at the Costa Rica site, and ultimately made available to remote and passive users throughout Latin America. The short courses are supplemented by monthly online training modules (described below). Finally, team mentors meet regularly with the project teams to continually improve program infrastructure and resources.

\section{Participants}

Two to four integrated teams per year, each consisting of three healthcare professionals and one technical (e.g., IT, statistical) person from a specific Low and Middle Income Country (LMIC), will be trained annually in the development and conduct of community engaged projects aimed at improving locally determined Maternal Health issues in their respective countries (Costa Rica, Dominican Republic, Honduras, and other LMICs over a 3-year training period).

In the first year, the course had 12 enrolled trainees including one team each from Costa Rica, the Dominican Republic, and Honduras. The cohort was composed of nurses, physicians, licensed engineers (technology) and masters' level hospital administrators. As required for the integrated team approach, each team had three healthcare professionals (including at least one physician), and one IT specialist. The personnel, country, and proposed project are listed in Table 1.

\section{Trainers and mentors}

The Universidad de Ciencias Médicas (UCIMED), a large medical School in San José, serves as the primary academic base for MundoComm. UCIMED has an active distancelearning portal for continuing education and is especially active in community-engaged service projects. Trainers and mentors included doctoral-prepared faculty from UCIMED, Costa Rica, the Dominican Republic and the
University of Rochester. Faculty from Costa Rica and the Dominican Republic speak Spanish as their primary language, and included physicians with additional postgraduate training in community and public health, informatics, and/or clinical investigation. While faculty and mentors from the University of Rochester were not bilingual (except for one who is originally from Puerto Rico), all trainings involving non-Spanish speakers and all English materials were presented with Spanish interpretation. University of Rochester faculty disciplines included: Anthropology, Nursing, Psychology, and Informatics.

\section{Technology}

\section{Online training platform}

Moodle (Modular Object-Oriented Dynamic Learning Environment), a freely available and popular open-source learning management system (LMS) or e-Learning platform that serves educators and learners, was developed in 2002 to help educators create online courses with a focus on interaction and collaborative construction of content [16-18]. The feasibility of using a such a globally networked learning environment (GNLE) is central to MundoComm's overall goals.

MundoComm trainees were asked to create names for their respective teams. This was implemented: 1) to promote the identity, cohesiveness, and effectiveness of each field team, and 2) to promote efficient and tailored faculty-team communication via the LMS. Four named groups were created within this platform, and the course faculty manually enrolled each trainee into his or her respective group. After trainees submitted their completed assignments online, course faculty were able to provide evaluation, instruction, and feedback specific for each team. Additional team-based organization regarding the timing and management of assignments was accomplished by controlling the visibility/accessibility of specific modules, comments, and postings.

\section{REDCap data collection and management}

In tandem with the Moodle ${ }^{\bullet}$ platform, online didactic assignments and evaluations were developed and implemented using REDCap ${ }^{\circ}$ (Research Electronic Data Capture), which is a software toolset and workflow

Table 1 Proposed Projects

\begin{tabular}{|c|c|c|}
\hline Country Team & Trainees & Proposed Project using TICS \\
\hline Costa Rica & 3 physicians, 1 IT specialists & $\begin{array}{l}\text { Evaluate impact of previous TICS projects on maternal and child health in } \\
\text { rural community }\end{array}$ \\
\hline Honduras & 1 physician, 1 administrator, 1 nurse, 1 IT specialist & Training in rural teen pregnancy prevention and post-partum follow-up \\
\hline Dominican Republic & 2 physicians, 1 administrator, 1 IT specialist & $\begin{array}{l}\text { Lower risk of premature births and assess effects of poor nutrition, toxemia, } \\
\text { and post-partum complications in low-resource areas }\end{array}$ \\
\hline
\end{tabular}


methodology for electronic collection and management of research and clinical trial data with a secure online format providing an easy-to-use interface for trainees to enter requested information and to provide feedback to the course faculty.

The Clinical Translational Science Institute (CTSI) Informatics Core, a unit of the University of Rochester School of Medicine and Dentistry's Academic Information Technology (AIT) Group, serves as a central facilitator for all data management, including project-specific data and iterative self-documenting processes by all members of the project team. REDCap ${ }^{\circ}$ was developed in a manner consistent with HIPAA security requirements.

\section{Modules and materials}

\section{Spanish back translation}

In order to create an equivalent and culturally appropriate Spanish language version of initial English versions, materials were first translated into Spanish, and then back translated into English using the Brislin method [19]. The Spanish versions were pre-tested during the back translation process by four bilingual investigators from the US and Costa Rica for readability, skip patterns, formatting, and content.

\section{The course}

Learning Objectives for the course are to: 1) provide the didactic and mentoring infrastructure to facilitate ICT innovations developed and tested for feasibility in community-based real-life settings; 2) infuse each institution and each of the trainee teams with new insights and strategies for working with diverse partners to create ICTs; 3 ) aid the teams and faculty to improve the efficiency of the development process via the Collaboratory concept of mentoring and social networking; and 4) strengthen the academic collaboration amongst the partners.

To address these Learning Objectives, a core educational plan over a 12-month timeframe was developed (Table 2) which includes two annual 1-week courses convened in Costa Rica (Table 3), and further supplemented with six online training modules, using the Moodle $^{\bullet}$ online training platform and mentored guidance. The online course comprises over 20 topics divided into the six modules - each module further segmented into three-four assignments, with each assignment being 1 to 2 weeks in duration. Assignments include readings and assigned tasks covering different aspects of community-engaged public health interventions. The content is peer reviewed by experts in the respective fields from University of Rochester, UCIMED in Costa Rica, and faculty from Costa Rica and the Dominican Republic who maintain regular contact with the trainees to mentor learning and project progress (Fig. 1). Attention was given throughout the short-course and online modules to best-practice recommendations for data management and security, and well as ethical considerations in the conduct of research. All participants completed an NIH ethics course as part of their training.

\section{ICT in maternal health I short course: technology}

The content areas of instruction identified for this population of medical learners include introductory-level skills and topics designed to train health and IT professionals for whom research is not a central job responsibility, but for whom understanding and basic implementation of research principles may help them to be more successful with their maternal health project development. The course was designed to help trainees be more knowledgeable and effective in developing novel technology-based interventions to serve their maternal health populations; to help them understand their project's data needs and to successfully organize their project from inception to pilot testing.

During the first week-long short course training in Costa Rica with teams from the Dominican Republic, Honduras and Costa Rica, didactic material was presented in person by United States, Costa Rica, and Dominican Republic faculty covering a wide range of introductory-level areas. The Introductory-level areas of instruction were identified from inspection of methodology courses offered on various online learning platforms, and input from content experts on the core project team, and colleagues within their professional networks. The content areas were then organized into overarching themes of instruction and more specific topics to be addressed via modules, as shown below, and placed either in the in vivo short-course format, or the online distance-learning platform (Moodle ${ }^{\circ}$ ). These themes were identified with the goal of providing an introductory experience, as appropriate for non-research professionals.

Overarching Themes: 1-Week Short Course (See Also Table 3)

1. Research and ICTs (Information and Communication Technologies) in Latin America.

2. ICTs in Maternal Health

3. Aspects of social, legal and ethical considerations in ICT.

4. Facilitated Global Health Ethics: bioethics program in Spanish.

5. Intelligent databases and data records.

6. Intelligent databases and data records: workshop with Google Forms. 
McIntosh et al. Global Health Research and Policy (2017) 2:8

Page 5 of 14

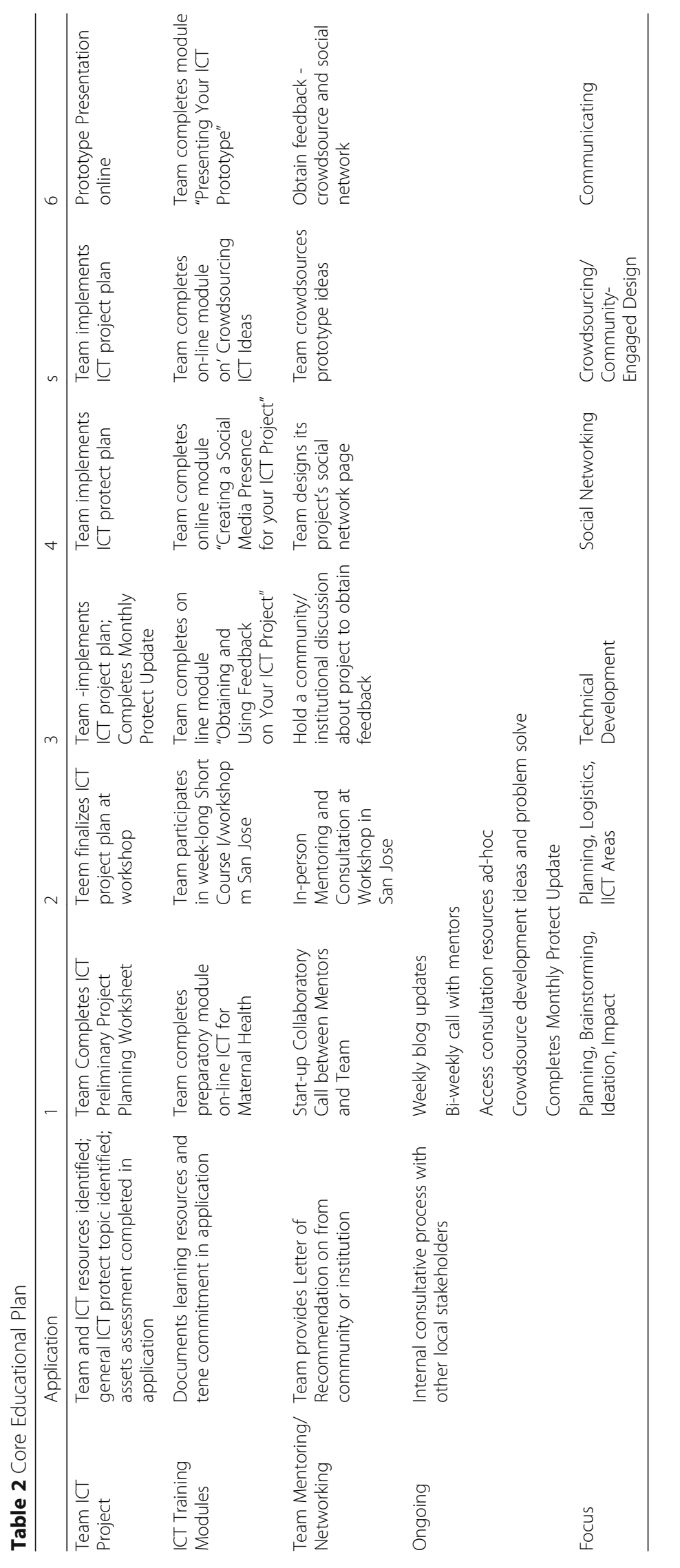




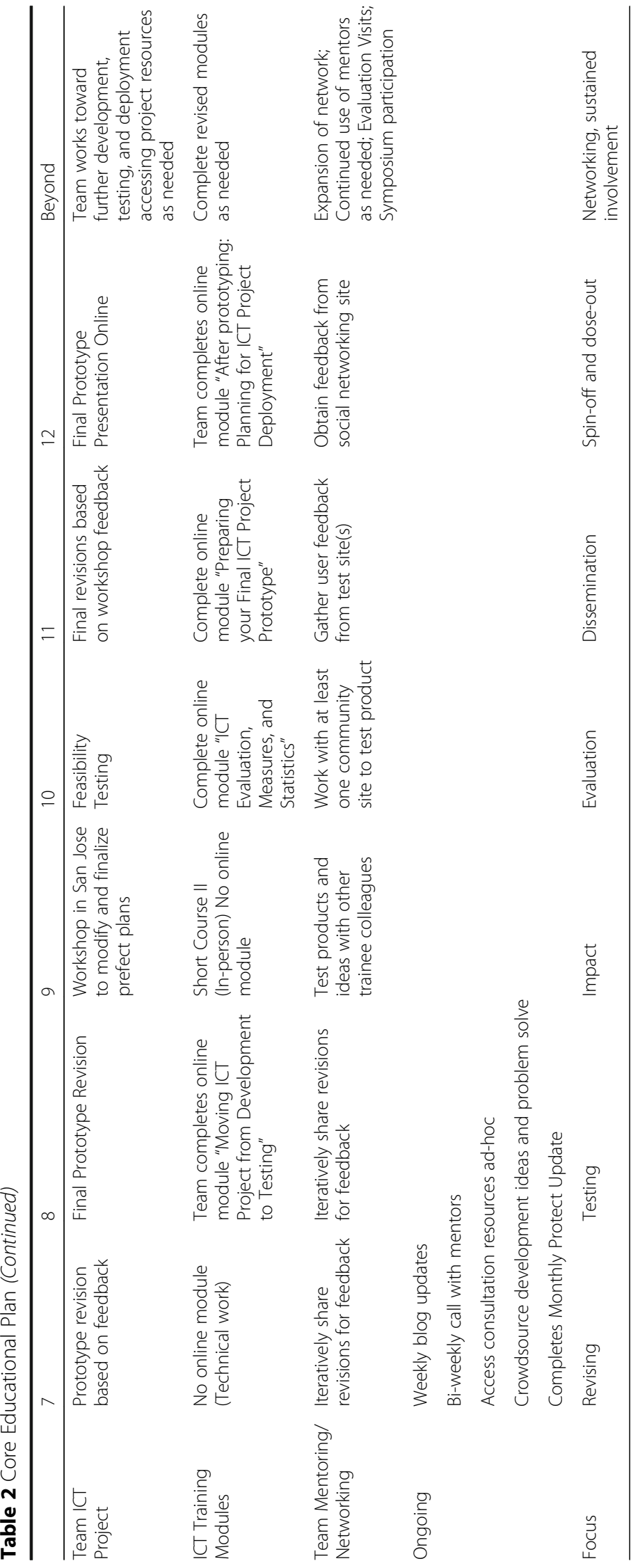




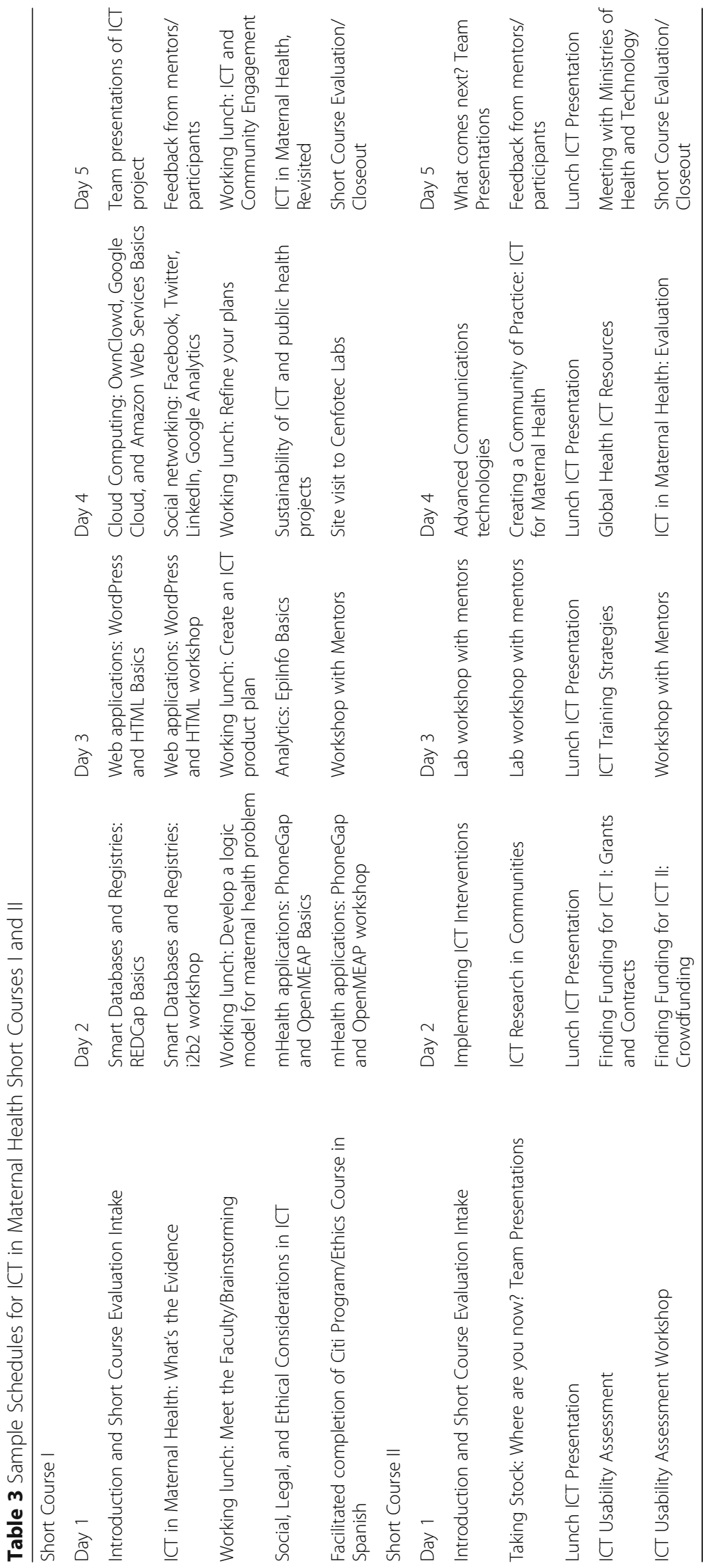


Módulo 1 Del 02112015 Al 30112015

\section{Participación de la Comunidad: Obtención y utilización de información sobre su proyecto de TIC.}

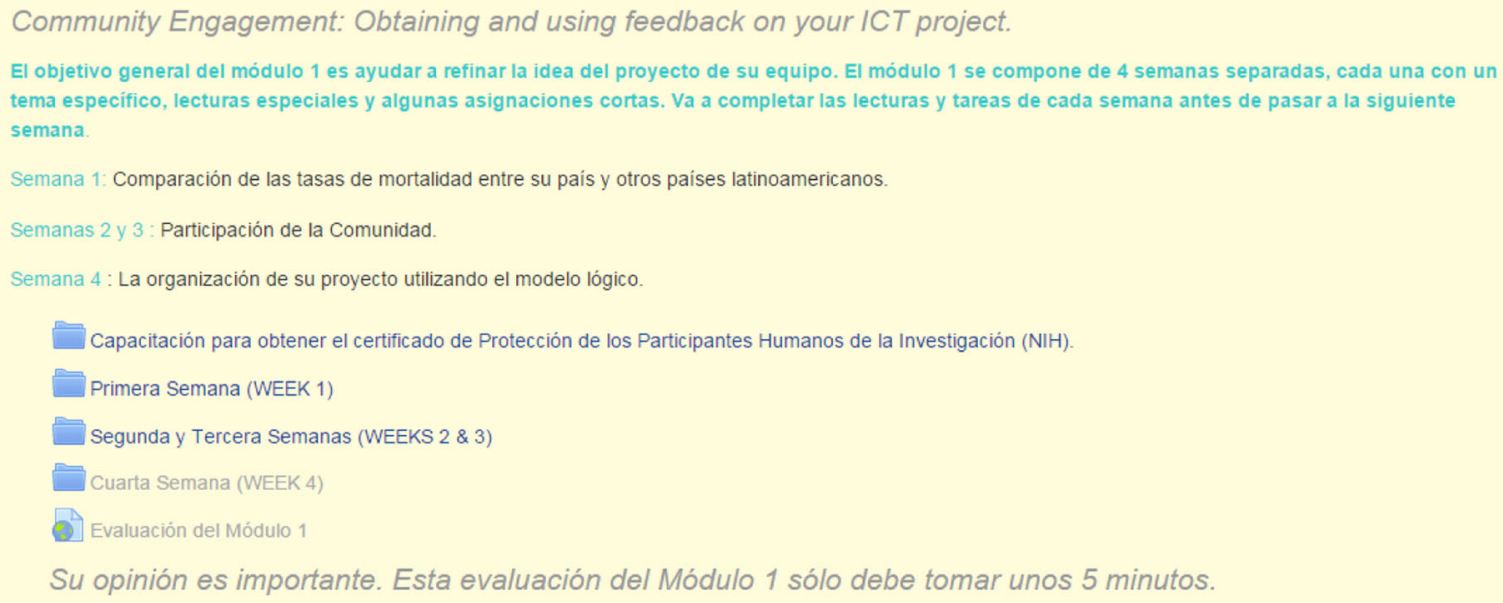

Fig. 1 Screen Shot: Online Module \#1

7. Development of a logic model to address a problem of maternal health.

8. Clinical research and databases.

9. Basics: Epi-Info ${ }^{\circ}$

10.How to create a plan for development of an ICT product.

11.Review and analysis tools for the evaluation and accompaniment of projects from the first year of MundoComm

12.Cloud (cloud) computing: OwnCloud ${ }^{\circ}$, Google Cloud $^{\circ}$ and Amazon Web Services ${ }^{\circ}\left(\mathrm{AWS}^{\circ}\right)$.

13.Introductory to Word Press ${ }^{\circ}$ and HTML.

14.Resetting and revision of work plans.

15.Other tools: Open MEAP ${ }^{\circ}$, Phone GAP ${ }^{\circ}$.

16.Use of social networks and community empowerment: Facebook ${ }^{\circ}$, Twitter ${ }^{\circ}$, LinkedIn ${ }^{\circ}$, Google Analytics.

17.The sustainability of projects and ICT.

Overarching Themes: Online Training (See Also Table 3)

1. Module 1: Community Engagement

2. Module 2: Social Media \& ICT Project

3. Module 3: Crowdsourcing ICT Prototype

4. Module 4: From development to testing

5. Module 5: ICT Evaluation, Measures and Statistics

6. Module 6: Final ICT Prototype

\section{Guided mentoring}

ICT technologies will be introduced throughout the year-long curriculum and focused especially in this first in-person Short Course. Faculty and technical team members (mentors) share expertise in these ICT areas and will draw upon one another when providing scheduled (and as needed) consultation and mentoring for the teams. Team mentors will assemble annually in Rochester and in Costa Rica to share new approaches, technological ideas, relevant advances in global health and biomedical research, and to continually improve program infrastructure and resources. Throughout the program, teams will collaborate with the mentors to develop their basic ICT intervention which addresses their identified maternal health issue.

\section{ICT in maternal health II short course: communications, evaluation}

During the second short course (Table 3) the teams are expected to have refined their projects and evaluation plans, including new ICT technologies and applications for future work. Teams will generate collaborative research ideas with faculty and technical advisors for future funding strategies. Additionally, they will learn to use global health ICT resources beyond Latin America.

The evaluation of online training and mentoring included longer-term outcomes (evaluation of Moodle $^{\circ}$ 
platform experience) and shorter-term outcomes: whether ICT innovations were developed and tested for feasibility in community-based real-life settings, whether the training program infused each institution and each of the trainee teams with new insights and strategies for working with diverse partners to create ICTs, whether the Collaboratory concept of mentoring and social networking aided the teams and faculty to improve the efficiency of the development process, and whether the academic collaboration amongst the partners strengthened. These outcomes directly relate to the project's four primary aims, as described above.

Evaluation of the short course and Moodle ${ }^{\circledast}$ online platform Using information technology for assessment (e-assessment) includes various strategies to evaluate trainee learning [20-22]. e-Assessment can be accomplished within a single-user system, via networks linked to specific servers, or directly online [23]. As with any assessment, e-assessment provides feedback to trainees about their progress and about whether they have met learning objectives [20].

A pre-training questionnaire and daily post-training evaluations were piloted with the 12 trainees in the first year, using a range of ratings and response choices. A post-training questionnaire was later provided to the first cohort prior to the beginning of their second face-to-face training, to assess the longer term online Moodle ${ }^{\circledast}$ platform experience.

\section{Results}

Trainees were assessed for knowledge and familiarity prior to the face-to-face workshop, and daily after each day's educational workshop activity. Baseline evaluation of the trainees $(n=8)$ indicated gaps in knowledge of ICTs (Mean: 4.7/10; Range: 2.8/10 to 6.0/10), with the highest familiarity reported for social networking. Although multiple reminders and encouragement were given to all 12 trainees, only six anonymously participated in immediate post-training assessments. Average scores indicated self-reported increases in knowledge across course content areas (see Table 4). A total of 10 participants replied to the post-training online Moodle ${ }^{\circ}$ experience evaluation (see below).

With respect to social media, the pre-training feedback indicated that trainees felt particularly competent in the understanding and use of various social media. At the end of the in-person, five day course, however, anecdotal feedback in a group discussion indicated that they felt their self-reported pre-training knowledge did not match with what they learned during the week. For example, they thought they understood social media well, but learned that social media can be used not just for one's own social interactions and entertainment, but as a
Table 4 Baseline and Immediate Post-Training Average Scores

\begin{tabular}{lc}
\hline Evaluation of Course Topics & $\begin{array}{c}\text { Average Scores Scale 1-10, } \\
\text { where: } 1=\text { Knows a Little } \\
10=\text { Knows a Lot }\end{array}$ \\
\hline Baseline knowledge of course topics & $4.7^{* *}$ \\
Prepared for Online Moodle ${ }^{\oplus}$ Modules & $5.8^{*}$ \\
Prepared for using REDCap & $6.7^{*}$ \\
Cloud Computing & $6.8^{*}$ \\
Word Press/HTML & $8.3^{*}$ \\
Other software/technology & $8.3^{*}$ \\
Social Networks and Community & $8.3^{*}$ \\
Empowerment & \\
${ }^{*} n=6 ; * * n=8$ & \\
Likert Scales were either 1-4 or 1-5. For purposes of comparison across \\
educational topics, all scores were all standardized to scores between 1 and 10
\end{tabular}

means of reaching their target populations and delivering a variety of interventions.

Feedback was also elicited on didactic presentations, on specific technologies and social networks (including Google Cloud ${ }^{\circ}$, Amazon Web Services ${ }^{\circ}\left(\mathrm{AWS}^{\circ}\right)$, Twitter ${ }^{\circ}$, Facebook ${ }^{\circ}$, etc.), distance learning platforms (e.g., Moodle ${ }^{\circ}$ ), and on public health models. Daily feedback was also elicited for specific presenters and events relevant to that day. For example, at the end of one of the training days, all of the trainees either "agreed" or "strongly agreed" with the statement: "Presentaron información actual y parecieron bien informados sobre el tema (They presented actual information and appeared to be well informed on the topics discussed)."

Other open-ended questions elicited specific feedback. For example:

\begin{tabular}{ll}
\hline Spanish & English \\
$\begin{array}{l}\text { Muy interesante el uso de aplicaciones } \\
\text { para la implementación de nuestros }\end{array}$ & $\begin{array}{l}\text { The use of applications for } \\
\text { implementation of our } \\
\text { proyectos }\end{array}$ \\
$\begin{array}{l}\text { Es muy interesante todo lo was very interesting } \\
\text { que han explicado para mi }\end{array}$ & $\begin{array}{l}\text { Everything that they have } \\
\text { explained to me was very } \\
\text { interesting }\end{array}$ \\
Proveer más ejemplares sobre & Provide more examples for \\
el primer tema & the first theme \\
El desarrollo del curso fue muy & The course development was \\
interesante y he aprendido mucho & very interesting and I learned \\
& a lot
\end{tabular}

Post-training evaluation of the online Moodle ${ }^{\bullet}$ course included the observations that 1) students completed online course assignments with prompts and encouragement from mentors as needed, and 2) at the end of the online coursework participants responded to overall evaluation questions of the online $\mathrm{MOODLE}^{\bullet}$ experience (see Tables 5 and 6). 
Table 5 Online Moodle ${ }^{\circledast}$ Course Evaluation Items*

\begin{tabular}{|c|c|c|c|}
\hline & \multicolumn{3}{|c|}{ Neither Agree } \\
\hline & Agree & Nor Disagree & Disagree \\
\hline In general, I was satisfied with the online Moodle ${ }^{\oplus}$ course. & $n=7(70 \%)$ & $n=1(10 \%)$ & $n=2(20 \%)$ \\
\hline I learned new things from this Moodle ${ }^{\oplus}$ course & $n=9(90 \%)$ & $n=0(0 \%)$ & $n=1(10 \%)$ \\
\hline I am confident that I can use the things I have learned in the Moodle ${ }^{\oplus}$ course & $n=9(90 \%)$ & $n=0(0 \%)$ & $n=1(10 \%)$ \\
\hline This Moodle ${ }^{\oplus}$ course teaches me important themes & $n=8(80 \%)$ & $n=1(10 \%)$ & $n=1(10 \%)$ \\
\hline I would recommend this Moodle ${ }^{\circledast}$ course to others & $n=7(70 \%)$ & $n=2(20 \%)$ & $n=1(10 \%)$ \\
\hline
\end{tabular}

${ }^{*} n=10$. All questions and answers were in Spanish. Responses, translated to English, are included here with corresponding subject " $\mathrm{n}$ 's" and percentage endorsements of Strongly Agree, Neither Agree Nor Disagree, Disagree, and Strongly Disagree. Strongly Agree and Agree were collapsed for this table and presented as "Agree". Strongly Disagree and Disagree were collapsed for this table and presented as "Disagree"

\section{Discussion}

MundoComm aims to address the primary issue of maternal health problems in Costa Rica and other LMICs in Latin America by addressing existing knowledge and practice gaps among its partners, and to improve the technological capacity of their community work and public health research to integrate real-world, significant problems, and for communities to become familiar with the innovation process and technological resources it can access to address its pressing problems.

The course and modules were developed to include best practices in Information and Communication Technologies (ICT) and e-Health strategies, appropriate ethical review and institutional involvement, proactive community engagement, and community interventions that are evidence-based. Evaluations (in-person and online) involve both quantitative and qualitative feedback. For example, to address "community engagement", a module specifically addressed maternal health data, community engagement, and project organization via assignments such as comparing their own country's data with data from other countries, how to conduct semi-structured qualitative interviews, and developing logic models.

ICT technologies have emerged rapidly within maternal and child global health communities $[8,9]$, and growing evidence indicates that ICT interventions can significantly improve maternal health in lower- and middle-income countries [24, 25]. For example, implementing basic perinatal registries to track maternal health patterns using analytics helps communities better identify effective strategies, track outcomes, and target high-risk areas [26, 27], while continually improving data quality [28]. The use of electronic health records, such as electronic perinatal medical records, have demonstrated maternal health improvement in under-resourced areas of the United States [29] and globally [30,31].

Websites form an important mechanism for dissemination of health information to women [32] whose usage differs from that of men [33], and can deliver effective wide-reaching interventions such as tobacco cessation $[34,35]$, and other risk behavior changes that are strongly linked to maternal health outcomes. Relatedly, social media connect pregnant and post-partum women to each other, and research shows this social media engagement may improve well-being [33], management of pregnancyassociated weight and nutrition [36]. Finally, ICT interventions need to be tailored with women's usability in mind, since research has shown post-partum women favor websites that have easy navigation, and that promote social interaction with others [37].

MundoComm therefore focuses on basic training across several technical areas of ICT (prioritizing Open

Table 6 Open Ended Evaluation Questions*

\begin{tabular}{|c|c|c|}
\hline Questions & Common Themes & Example Quotes \\
\hline \multirow[t]{3}{*}{$\begin{array}{l}\text { What are the } 3 \text { most important things you } \\
\text { learned from the Moodle course? }\end{array}$} & Crowdsourcing & $\begin{array}{l}\text { How crowdsourcing could help us with the evaluation and users' } \\
\text { information on a research study }\end{array}$ \\
\hline & ICTs (Health Related) & The importance of the use of ICT's in maternal health) \\
\hline & Building a Logic Model & How to design a logic model \\
\hline \multirow[t]{2}{*}{$\begin{array}{l}\text { What could be improved for this Moodle } \\
\text { Course? }\end{array}$} & Moodle ${ }^{\oplus}$ platform & $\begin{array}{l}\text { The access to upload or to send assignments should be less } \\
\text { complicated to students }\end{array}$ \\
\hline & Language difficulties & Some pages were only in English \\
\hline $\begin{array}{l}\text { Do you have any other comments for this } \\
\text { Moodle }{ }^{\ominus} \text { course? }\end{array}$ & Courses and Research & $\begin{array}{l}\text { I think these types of courses should always be available, they } \\
\text { increase the knowledge and help to resolve problems according } \\
\text { to the topics or projects that can be investigated }\end{array}$ \\
\hline
\end{tabular}

${ }^{*} n=10$. All questions and answers were in Spanish. Themes were identified for inclusion when at least two respondents endorsed a particular theme. Exemplary respondent quotes, translated to English, are included here 
Access and free tools): Databases (REDCap ${ }^{\circ}$ ) and Analytics $\left(E^{\circ} \operatorname{linfo}^{\circ}\right.$ ); Electronic Health Records (e.g., electronic perinatal medical records); HTML/Web Site Design (WordPress ${ }^{\circ}$ ); Mobile App development (PhoneGap ${ }^{\circ}$, OpenMEAP ${ }^{\circ}$ ); and Social Media (Facebook ${ }^{\circ}$, Twitter ${ }^{\circ}$, LinkedIn', Google Analytics $\left.{ }^{\circ}\right)$. As "Cloud Computing" may provide a paradigm shift in how low-resource communities may access and use a wide range of tools and technical details [38], the training will also introduce such Cloud Computing options as OwnCloud ${ }^{\circ}$, Amazon Web Services ${ }^{\circ}$, and Google Cloud ${ }^{\circ}$. Beyond the current project, the long-term impact is expected to include development and scale-up of ICT interventions that improve maternal health, in the sustained, collaborative context of multidisciplinary stakeholders. Online tools used in MundoComm were selected in part with consideration to being user-friendly, with various interactive features, and maximum flexibility. For example, RED$\mathrm{Cap}^{\circ}$ was used for a variety of purposes, including initial team applications, uploading documents, and evaluations of face-to-face and online modules. This tool can be accessed and used for data capture from a variety of devices, both online and offline [39].

With respect to MundoComm's four aims, described above, the current program has already demonstrated 1) the feasibility of implementing a mentored training program for community-based public health applied research teams in LMICs, with specific reference to maternal health; 2) the implementation of specific training team ICT innovations in field settings (resulting in the eventual completion of each team's proposed ICT project); 3) the creation of a "Collaboratory" environment where teams, faculty, experts, and others to share developing material and processes; and 4) the promising development of a professional network of ICT, medical, public health, and community students, faculty, researchers, and practitioners devoted to supporting ICT for maternal health in LMICs. If ongoing evaluation in this and related projects can provide a "proof of concept", the present mixed model of training with the use of technology (i.e. online courses for distance learning and mentoring learners with only 2 weeks of face to face contact) is potentially feasible and sustainable in LMICs.

As described by Heller et al. [1], in the context of education, students are not just recipients but are actively involved in collaboration in learning activities, often expressed as Web 2.0, eLearning 2.0 or Education 2.0. The emergence of Education 3.0 [40], they posit, is considered to be an extension of this, where open-access materials are created and adapted by various collaborating groups and individuals - including the students. These thoughts are consonant with MundoComm's four primary aims, particularly with respect to the creation of a "Collaboratory", and with the incorporation of feedback from trainees as part of our iterative curricular development.

\section{Challenges}

Maximizing novel approaches to online training and program management both in the US and country-specific requires experimentation with sophisticated technologies including multi-media presentation of didactic material, distance learning strategies, and the use of iPads for offline data collection in global settings. Although comparing and selecting optimal media, strategies, software and hardware would have been ideal for enhanced project fidelity; this was not fully possible due to the project's timeline and available resources.

Although useful as a qualitative assessment of feedback from this first cohort, the Likert style items will be refined and standardized for future cohorts, incorporating trainee feedback. These will be administered to subsequent cohorts to quantitatively assess measurable prepost changes in self-rated scores. For the first cohort however, where Likert ranges included both 1-4 and 1-5 response choices, standardized proportional scores (1-10) were calculated from average scores for simple comparison purposes.

\section{Lessons learned}

For faculty there was a steep learning curve, initially, as the online platform had parallel but different features than other LMS systems used previously - coupled with the fact that initial instruction on the use of Moodle ${ }^{\circ}$ was in Spanish only, and based on the host institution's online virtual environment/version of Moodle ${ }^{\circ}$. Not unexpectedly, there were challenges to creating, implementing, and tracking online systems for both educational and data collection purposes. Preliminary evaluation data indicate overall satisfaction with the course format (both in-person short courses, and online didactic components) and the content presented.

\section{Future directions}

The second in-person short course will come in the ninth month of the training program, approximately 5 months after the first short course, described above. By that time, the trainee teams will be entering the last phase of their intervention development. The second short course will be focused more on bringing team projects toward closure and evaluation, and introducing new concepts and technologies. It will also feature more time with mentors and advisors in multiple interactive workshop settings, with a focus on resolving details and expanding on project ideas. Online training will continue with the six modules described above, and will overlap with this second in-person short course. Both the latter online modules and the second short course will continue to be informed by our 
ongoing iterative curricular developmental process involving evaluation feedback from trainees, project staff, and other stakeholders. The final outcome (self-reported community involvement, project pilot development, etc.), will be measured 1 year after the end of the second short course. Given the flexibility and availability of our primary course platforms and tools (e.g., Moodle ${ }^{\circ}$ and REDCap ${ }^{\circ}$ ), future courses can be expanded upon and/or scaled up as appropriate. Such tools can easily accommodate multiple designers, didactic tools (including an increasing variety of multi-media options), and evaluation strategies.

As the aims of MundoComm are to train and demonstrate the successful use of ICTs for maternal health improvement in LMICs, evaluation efforts at the conclusion of the training will assess trainees' perceived learning of evidence-based strategies to decrease maternal health disparities and the degree of incorporation of valid evaluation strategies to assess the impact of each project's initiative on appropriate measurable health outcomes.

Determinants of the reproducibility of the present model include start-up costs and the availability of online technological resources. Costs in the present model can be minimal, as there are advantages to using existing online coursework platforms through partnering institutions (MOODLE ${ }^{\circ}$, REDCap$^{\circ}$ ), although time was needed for communicating across international teams to address issues related to troubleshooting and access to training models for all faculty, mentors, and trainees. Programs should establish a stable and accessible learning platform and project teams should be able to have ongoing reliable access to the internet.

Consistent with the tenets of CBPR (Community Based Participatory Research) and of our previous work $[4-6,11]$, there are a number of factors that all serve to increase the likelihood of community uptake and the reliability of transporting infrastructure such as the present model more broadly. These include: 1) the use of field teams embedded in communities in which their projects were developed, 2) team selection based on a maternal health topic relevant to their community, and 3) community engagement supported throughout the process of project development.

\section{Conclusion}

Initial evaluations and feedback during the implementation phase suggest that, in combination with in-person learning, an online training platform and e-assessment strategies can be feasible for delivering targeted didactic material. The present study preliminarily evaluates feasibility, usability and progress towards MundoComm's aims and learning objectives. The advantages to the type of online strategies employed, such as striving for usability, cultural appropriateness, and the incorporation of a variety of interactive features to enhance the learning experience, can help inform future initiatives towards maximizing flexibility in training. With ongoing feedback from all stakeholders, including trainees, additional functionality and efficacy can be pursued. Lessons learned from this training experience include the development of better practices to ensure more complete evaluations, such as assigning unique user identification credentials to participants to anonymously track their participation and secure evaluation feedback.

Our multidisciplinary approach to training with faceto-face didactics and distance learning strategies resulted in the implementation of a model-based course for training maternal health professionals, the process of which can potentially be exportable to other settings. Newer interfaces for online training will help us fully optimize e-learning as a mode of delivery for global learning.

The community-engagement process links teams with their primary stakeholders, communities and institutions [14]. By involving community perspectives into creative ideation, project design, and revision, team members are facilitating accountability for completing their projects, with the encouragement and involvement of the community. When institutions and communities are aware of, supportive of, and involved in a team's work, teams are even more likely to be motivated to complete the work and be accountable for its outcome. Additionally, all team materials are housed and shared within the Collaboratory virtual space, such that others from outside MundoComm and new trainees within it can access them. This opensource perspective further fosters a sense of collaborative purpose and shared vision.

Finally, trainees will emerge as thought-leaders who are knowledgeable around issues of ICT in maternal health and, to a broader degree, public health. These individuals are likely to continue their relationships with their mentors and remain involved with MundoComm through its social network of professionals and stakeholders. Given the level and role of trainees in their institutions and in their communities, investing in their training and promoting research partnerships with the major institutions of medicine and technology involved with this project will enhance the project's ability to continue momentum in the future.

\footnotetext{
Abbreviations

AIT: Academic Information Technology; AWS: Amazon Web Services ${ }^{\oplus}$; CBPR: Community Based Participatory Research; CER: Community-Engaged Research; CTSI: Clinical Translational Science Institute; GNLE: Globally networked learning environment; HIPAA: Health Insurance Portability and Accountability; HTML: Hypertext markup language; ICT: Information and communication technology; IRB: Institutional review bard; IT: Information technology; LMIC: Low and middle income countries; LMS: Learning management systems; MOODLE ${ }^{\oplus}$ : Modular Object-Oriented Dynamic Learning Environment; MundoComm: Training initiative funded by the National Institutes of Health; $\mathrm{NIH}$ : National Institutes of Health; REDCap ${ }^{\oplus}$. Research Electronic Data Capture; RSRB: Research Subjects Review Board; TLT: Team Learning Theory; UCIMED: Universidad de Ciencias Médicas; US: United States
} 


\section{Acknowledgements}

The authors thank CTSI and UCIMED for technical support. They also thank the short course faculty and the trainee participants for their contributions, as well as the students who contributed to MundoComm, especially Andrew Tarbox.

\section{Funding}

This work was supported and funded by The National Institutes of Health/ Fogarty International Center Grant \#1 R25 TW 009697-01A1 (PI: Dye/Ossip). Further, Drs. Dye Demment receive funding from Award Number Grant UL1 TR000042 from the National Center for Advancing Translational Sciences, National Institutes of Health. The content is solely the responsibility of the authors and does not necessarily represent the official views of the National Center for Advancing Translational Sciences or the National Institutes of Health. All authors had full access to all the data in the study and take responsibility for the integrity of the data and the accuracy of the data analysis. The corresponding author had final responsibility to submit the report for publication.

\section{Availability of data and materials}

All available statistical data will be stored in secure digital files for seven years. There were no hard copy materials.

\section{Authors' contributions}

SMc prepared the abstract and first draft of the paper, with content contributed by SMC, TDVD, DJO, JGPR, TD, EA and MMD. The paper was revised by SMC, TDVD, DJO, and JGPR. Detailed plans regarding the short course and the online course were prepared by all authors and revised by SMc, JGPR, DJO and TDVD. Final draft of the paper was prepared by SMC and JGPR, and reviewed by all authors. All authors read and approved the final manuscript.

\section{Competing interests}

The authors declare that they have no competing interests. The work was conducted in the absence of any commercial or financial relationships that could be construed as a potential conflict of interest.

\section{Consent for publication}

All authors consent to the publication of the manuscript in Global Health Research and Policy, should the article be accepted by the Editor-in-chief upon completion of the refereeing process.

\section{Ethics approval and consent to participate}

The University of Rochester's Institutional Review Board, RSRB (Research Subjects Review Board) reviewed the project and determined that the project does not qualify as human subjects research (45 CFR 46.102) in that the activities do not meet the federal definition of research.

\section{Author details}

'Department of Public Health Sciences, University of Rochester Medical Center, 265 Crittenden Blvd., CU 420644, Rochester, NY 14642, USA. ${ }^{2}$ Department of Obstetrics and Gynecology, University of Rochester Medical Center, Rochester, USA. 'Department of Nursing, the College at Brockport, State University of New York, Rochester, NY, USA. ${ }^{4}$ University of Rochester School of Nursing (URSON), Rochester, NY, USA. ${ }^{5}$ Department of Obstetrics \& Gynecology - University of Rochester Medical Center, Rochester, NY, USA. 6UCIMED, San José, Costa Rica.

Received: 25 May 2016 Accepted: 7 February 2017

Published online: 01 March 2017

\section{References}

1. Heller RF, Chongsuvivatwong V, Hailegeorgios S, Dada J, Torun P, Madhok R, Sandars J, on behalf of the People's Open Access Education Initiative. Capacity-building for public health: http://peoples-uni.org. Bull World Health Organ. 2007;85(12):901-80.

2. Rodríguez-Clare A. Costa Rica's development strategy based on human capital and technology: how it got there, the impact of Intel, and lessons for other countries. J Hum Dev. 2001;2(2):311-24.

3. Dutta S, Bilbao-Osorio B. The Global information technology report 2012: Living in a hyperconnected world. 2012.
4. Dozier AM, Ossip-Klein DJ, Diaz S, Chin NP, Sierra E, Quiñones Z, Dye TD, McIntosh S, Armstrong L. Tobacco use in the Dominican Republic: understanding the culture first. Tob Control. 2006;15(Suppl_1):i30-6.

5. Ossip-Klein DJ, Fisher S, Diaz S, Quinones Z, Sierra E, Dozier A, Mclntosh S, Guido J, Winters P, Diaz O, Armstrong L. Tobacco use in six economically disadvantaged communities in the Dominican Republic. Nicotine Tob Res 2008;10(5):851-60

6. McIntosh S, Sierra E, Dozier AM, Diaz S, Quiñones Z, Primack A, Chadwick G, Ossip-Klein DJ. Ethical review issues in collaborative research between US and low-middle income country partners: A case example. Bioethics. 2008;22(8):414-22.

7. Hogan MC, Foreman K, Naghavi M, et al. Maternal mortality for 181 countries, 1980-2008: a systematic analysis of progress towards millennium development goal 5. Lancet. 2010;375(9726):1609-23.

8. Parker RM, Dmitrieva E, Frolov S, Gazmararian JA. Text4baby in the United States and Russia: an opportunity for understanding how mHealth affects maternal and child health. J Health Commun. 2012;17(sup 1):30-6.

9. Tamrat T, Kachnowski S. Special delivery: an analysis of mHealth in maternal and newborn health programs and their outcomes around the world. Matern Child Health J. 2012;16(5):1092-101.

10. Edmondson AC, Dillon JR, Roloff KS. 6 three perspectives on team learning: outcome improvement, task Mastery, and group process. Acad Manag Ann. 2007;1(1):269-314.

11. Minkler M. Community-based research partnerships: challenges and opportunities. J Urban Health. 2005;82(2):ii3-ii12.

12. Walsham G, Sahay S. Research on information systems in developing countries: current landscape and future prospects. Inf Technol Dev. 2006;12(1):7-24.

13. Van Weert T, Pilot A. Task-based team learning with $I C T$, design and development of new learning. Educ Inf Technol. 2003;8(2):195-214.

14. Ramírez R, Helen A, Galin K, Donald R. Community Engagement, Performance Measurement and Sustainability: Experiences from Canadian Community-Based Networks. Can J Commun. 2005;30(2):259-79.

15. Wulf WA. The collaboratory opportunity. Science. 1993;261(5123):854-5.

16. Dougiamas M, Taylor P. Moodle ${ }^{\oplus}$ using learning communities to create an open source course management system. In: Lassner D, McNaught C, editors. World conference on educational multimedia, hypermedia and telecommunications 2003. Honolulu, HI: Assoc. for the Advancement of Computing in Education; 2003. p. 171-8.

17. Moodlerooms. What Is Moodle \& What Is it Used for? At: http://www. moodlerooms.com/community-initiatives/what-is-moodle. Accessed Nov 252015.

18. Seluakumaran $\mathrm{K}$, Jusof FF, Ismail R, Husain R. Integrating an open-source course management system (Moodle ${ }^{\oplus}$ ) into the teaching of a first-year medical physiology course: a case study. Adv Physiol Educ. 2011;35:369-77.

19. Brislin RW. Back-translation for cross-cultural research. J Cross Cult Psych. 1970;1:185-216. doi:10.1177/135910457000100301.

20. Bull J, McKenna C. Blueprint for computer-assisted assessment. London: Routledge Farme; 2004. Google Scholar.

21. Qualifications and curriculum authorities: regulatory principles for e-assessment. London: Qualifications and Curriculum Authority; 2007. http://www.publications. parliament.uk/pa/cm200607/cmselect/cmeduski/memo/test\&ass/ucm3102 paper4.pdf. Accessed 25 Nov 2015.

22. El Tantawi MM, Abdelsalam MM, Mourady AM, Elrifae IM. e-Assessment in a limited-resources dental school using an open-source learning management system. J Dent Educ. 2015;79(5):571-83.

23. Conole G, Warburton B. A review of computer-assisted assessment. ALT-J Res Learn Technol. 2005;13(1):17-31.

24. Hampton T. Recent advances in mobile technology benefit global health, research, and care. JAMA. 2012;307(19):2013-4.

25. Donner J, Mechael P. mHealth in Practice: Mobile technology for health promotion in the developing world. A\&C Black; 2013.

26. Lopez AD, Mathers CD, Ezzati M, Jamison DT, Murray CJ. Global and regional burden of disease and risk factors, 2001: Systematic analysis of population health data. Lancet. 2006;367(9524):1747-57.

27. Bhutta ZA, Chopra M, Axelson H, et al. Countdown to 2015 decade report (2000-10): taking stock of maternal, newborn, and child survival. Lancet. 2010;375(9730):2032-44.

28. Lawn JE, Gravett MG, Nunes TM, Rubens CE, Stanton C. Global report on preterm birth and stillbirth (1 of 7): definitions, description of the burden and opportunities to improve data. BMC Pregnancy Childbirth. 2010;10(Suppl 1):S1. 
29. Lu MC, Kotelchuck M, Hogan VK, Johnson K, Reyes C. Innovative strategies to reduce disparities in the quality of prenatal care in under-resourced settings. Med Care Res Rev. 2010;67(5 suppl):198S-230S.

30. Phelan ST. The prenatal medical record: purpose, organization and the debate of print versus electronic. Obstet Gynecol Clin N Am. 2008;35(3):355-68.

31. Chi BH, Vwalika B, Killam WP, et al. Implementation of the Zambia electronic perinatal record system for comprehensive prenatal and delivery care. Int J Gynecol Obstet. 2011;113(2):131-6.

32. Edejer TT-T. Disseminating health information in developing countries: the role of the internet. BMJ. 2000;321(7264):797-800.

33. Hilbert M. Digital gender divide or technologically empowered women in developing countries? A typical case of lies, damned lies, and statistics, Paper presented at: Women's Studies International Forum. 2011.

34. Norman CD, McIntosh S, Selby P, Eysenbach G. Web-assisted tobacco interventions: empowering change in the global fight for the Public's (e)health. J Med Internet Res. 2008;10(5):e28.

35. Stearns M, Nambiar S, Nikolaev A, Semenov A, Mclntosh S. Towards evaluating and enhancing the reach of online health forums as a treatment of smoking. Netw Mod Anal Health Informatics Bioinform. 2014;3(1):1-11. doi:10.1007/s13721-014-0069-7.

36. Hearn L, Miller M, Fletcher A. Online healthy lifestyle support in the perinatal period: What do women want and do they use it? Aust J Prim Health. 2013;19(4):313-8.

37. Nellsch ER, Walker LO, Xie B, Vaughan MW. What New Mothers' favorite Web sites and features tell Us about designing Web-based health promotion: a content analysis. Telemed e-Health. 2013;19(11):875-8.

38. Kshetri N. Cloud computing in developing economies. IEEE Comput. 2012:43(10):47-55.

39. Mclntosh S, Pérez-Ramos J, Demment MM, Vélez Vega CM, Avendaño E, Ossip DJ, Dye TD. Development and implementation of culturally tailored offline mHealth surveys. J Med Internet Res. 2016;2(1):e28.

40. Keats D, Schmidt J. The genesis and emergence of Education 3.0 in higher education and its potential for Africa. First Monday. 2007. Available at: http://www.firstmonday.org/issues/issue12_3/keats/index.html

\section{Submit your next manuscript to BioMed Central and we will help you at every step:}

- We accept pre-submission inquiries

- Our selector tool helps you to find the most relevant journal

- We provide round the clock customer support

- Convenient online submission

- Thorough peer review

- Inclusion in PubMed and all major indexing services

- Maximum visibility for your research

Submit your manuscript at www.biomedcentral.com/submit 